\title{
Mediating Effects of Financial Innovations between Behavioral Factors and Financial Inclusion of Micro Enterprises in Kenya
}

\author{
Gladys Byegon 1*, Dr. Josephat Cheboi ${ }^{2}$, Dr. Ronald Bonuke ${ }^{3}$ \\ 1,2,3 Moi University, Kenya \\ * Corresponding author: gladchero10@gmail.com
}

\begin{abstract}
Article History
Received 2019-09-10

Revised 2019-10-14

Revised 2019-10-26

Accepted 2019-11-06

Published 2019-11-20

\section{Keywords \\ Financial Inclusion \\ Behavioral factors \\ Self-control \\ Confidence \\ Social Proof \\ Financial Innovations}

\section{How to cite?}

Byegon, G., Cheboi, D. J., \& Bonuke, D. R. (2019). Mediating Effects of Financial Innovations between Behavioral Factors and Financial Inclusion of Micro Enterprises in Kenya. SEISENSE Journal of Management, 2(6), 49-64. doi: $10.33215 /$ sjom.v2i6.227

Copyright (C) 2019 The Author(s) (cc) BY

\section{Abstract}

Purpose: Understanding the mediating role of the adoption of financial innovations on the relationship behavioral factors and utilization of formal financial services was the main aim of this research. The behavioral factors examined were self-control, confidence and social proof. The study is premised on behavioral finance theories.

Design/Methodology: The positivist approach and explanatory research designs were adopted to understand the relationships between the variables under investigation. A sample of 486 owners/managers of licensed micro-enterprises in Nairobi, Kenya were selected using stratified random sampling technique. Primary data was collected through a structured questionnaire. Hypotheses were tested using Hayes and Zhao approach for mediation analysis.

Findings: The results showed that financial innovations mediated the relationship between each of the behavioral factors and financial inclusion, that is; self- control $(\beta=.0941, \varrho=.00)$, confidence; $(\beta=.1019, \varrho=.00)$ and social proof $(\beta=.1036, \varrho=$ $.00)$.

Practical implications: The study has brought into fore the mediating role of financial innovations on the relationship between the three behavioral factors and financial inclusion. Thus, practitioners are encouraged give due attention to behavioral factors and financial innovations in policy formulation and programs geared towards optimal utilization of financial services. 


\section{Introduction}

Financial Inclusion (FI) generally viewed as the process of enhancing access and usage (Jukan \& Softic, 2016; Sarma, 2008) of formal financial services has emerged as an area of global concern and study. Whereas the benefits of financial inclusion at micro and macro levels are generally understood, studies on factors that drive enhanced usage of diverse types of financial services are emerging as a key area of investigation in the global arena. (Demirguc-Kunt, Klapper, Singer, Ansar, \& Hess, 2018; Grohmann, 2018; Park \& Mercado, 2015; Sethi \& Acharya, 2018). Presently, studies on the FI concept continue to emerge with the focus being on factors that drive financial inclusion or its antonym (financial exclusion). For example, Chambers (2010) observed that conducive legal and regulatory environment would enhance FI, whereas Karp and Nash-Stacey (2015) recognized that FI continues to be a challenge for many communities and households and observed that technology (mobile, internet, and computer access) as a key enabler in the U.S. metropolitan areas. African countries continue to register growth in access to FI due to development in the financial sector, including adoption of emerging technologies such as mobile money transfers and banking, albeit behind their developed peers (Faye \& Triki, 2013).

Emerging financial innovations (FINN) such as agency and mobile banking, among others have been theorized as enablers of FI, but empirical studies on the relationship between the variables are scanty. (Cadena \& Schoar, 2011; Francis, Blumenstock, \& Robinson, 2017; Ozili, 2018). Studies suggest that FINN has the potential of fostering positive behavioral factors and financial discipline; for example reminders through short message service (SMS) may lead to increased savings (Karlan, McConnell, Mullainathan, \& Zinman, 2016; Kast, Meier, \& Pomeranz, 2018) and enhanced loan repayment (Cadena \& Schoar, 2011; Jones, Loibl, \& Tennyson, 2015; Karlan, Morten, \& Zinman, 2012). Also, scholars have highlighted the impact of FINN on modification of behavior for enhanced usage of financial services such as encouraging savings by appealing to peoples' gambling tendencies as well as provision of price or lottery linked financial products or accounts. (Abraham, Akbas, Ariely, \& Jang, 2016; Atalay, Bakhtiar, Cheung, \& Slonim, 2014). These studies suggest that financial innovations could likely have a mediating role in the relationship between behavioral factors and utilization of formal financial services in the era of emerging technology-driven financial products and intermediary channels in Kenya.

New empirical studies have considered different behavioral factors and their influence in the use of financial services albeit with mixed results. For example, Lown, Kim, Gutter, and Hunt (2015) observed that self-efficacy (Confidence) had significant effect on savings, while Meier and Sprenger (2010) found out that lack of selfcontrol results in massive credit due to present-biased preferences. Also studies on the relationship between behavioral factors and financial inclusion are at nascent stages (Barber \& Odean, 2007; Binoy \& Subhahree, 2018; Jurevičienè \& Ivanova, 2013), yet Behavioral Finance Theories (BFT) attest that these factors affect economic decisions. Furthermore, there is an emptiness of empirical studies ton the mediating effects of adoption of financial innovations on the relationship between behavioral factors and FI. Hence, anchored on Behavioral Finance Theories (BFT), the study diverted from the commonly studied decision-making on investments traded in securities markets and explored the interaction between three sets of behavioral factors (self-control, confidence and social proof), all derived from prior studies, and financial inclusion among microenterprises (ME) in Kenya. These economic actors (ME) have been less studied, yet they face constraints in accessing formal financial services and are key players in emerging economies.(KNBS, 2016).

Therefore, the primary purpose of the study was to examine the mediating role of adoption of financial innovations on the relationship behavioral factors (self-control, confidence and social proof) and utilization of formal financial services. The relationship between each of the behavioral factors, mediator, and FI was examined separately. Thus, the study sought to find out whether financial innovations have significant mediating 
effects on the relationship between Self-control and FI, Confidence, and FI as well as Social proof and FI of Micro Enterprises in Kenya. Based on the empirical studies above and to the best of our knowledge, a comprehensive model that aims at understanding the extent to which BF (self-control, confidence, and social proof) influences FI, directly or indirectly through FINN as modeled by Hayes (2013), has scarcely been explored, hence this study contributed to knowledge creation on drivers of FI from a developing economy perspective. The conclusions of this study demonstrate the significant effects of behavioral factors and the mediating role of financial innovations. Hence the recommendations are worthy of consideration by finance policymakers, financial institutions, and scholars in their quest to contribute to enhanced financial inclusion for improved quality living and realization of economic growth.

\section{Literature Review}

Earlier scholars viewed FI as the processes that improve access to the financial system by the poor and disadvantaged social groups. (Thrift \& Leyshon, 1999). In scholarly and policy fora, ownership of an account at a formal financial institution (FFI) such as a bank, credit union, cooperative, post office, or microfinance institution or a mobile money account is acclaimed as the main indicator of access to financial services (Demirguc-Kunt et al., 2018). The focus on ownership of an account stems from the argument that ownership of such an account forms the debut into the formal financial sector and that FI improves an individual's economic status and quality of life at the micro-level while contributing to economic growth at macro level. (Neaime \& Gaysset, 2018; Olaniyi \& Babatunde, 2016; Zins \& Weill, 2016). FI has been theorized in several dimensions; ownership of an account (access), quality (relevance of FS to the consumer), usage (permanence and depth of usage of FS), and welfare that focuses on impact of FS on the user. (Jukan \& Softic, 2016; Sarma, 2008). Due to growing interests in dissecting factors that determine the level of FI from both users and providers of financial services (FS) point of views (Allen, Demirguc-Kunt, Klapper, \& Peria, 2016) among others, this study focused on the usage dimension, which moves beyond the commonly studied aspect of access, given that it is through usage that benefits of financial services are accrued.

Some of the factors that have been conjectured as drivers of financial exclusion in developing economies include inadequate money, high user fees for the various services, lack of appropriate documentation such as ownership documents, and lengthy distance to location of service providers. (Demirguc-Kunt \& Klapper, 2012) Lanie (2017). Demographic factors such as gender, wealth, education levels, and age have been attributed to diversity in ownership and usage of accounts. (Olaniyi \& Babatunde, 2016; Zins \& Weill, 2016). Strömbäck, Lind, Skagerlund, Västfjäll, and Tinghög (2017), investigated the effect of individual differences in self-control, optimism, deliberative thinking in financial decision-making. The findings suggest that people with good selfcontrol are more likely to save money earned, have better general financial behavior, feel less anxious about financial matters, and feel more secure in their current and future financial situation. Optimism and deliberative thinking were found to have positive effects on savings behavior independent of self-control. Binoy and Subhahree (2018), undertook an exploratory research on behavioral factors that influence the continued usage of formal financial services among the low Income households in India using behavioral finance theories. The study concluded that impulsiveness, commitment to goals, social proof, self-efficacy, and comfort level besides privacy concerns had a strong relationship with continued usage of formal financial services among the Low Income Households.

Behavioral Finance Theories (BFT), which is an intersection of the fields of psychology and sociology with the science of finance, is traced to the 1890s. Earlier scholars such as Le Bon (1896) in Jurevičiene and Ivanova (2013) is recognized to be one of the pioneer scholars to suggest that investors demonstrate irrational behaviors in their actions. This was informed by the realization that many anomalies in the markets are the results of psychological factors, which are inherent in decision-making. Zaleskiewicz (2006) suggests that there are two main categories of behavioral finance theories; belief-based (cognitive deviation theories) which focuses on 
judgments (thoughts and perceptions) concerning risks and expected returns, and preference-based (preference theories) which concerns itself with decisions on what as well as when to trade. Cognitive deviations can be further sub-divided into four groups: heuristics, framing, emotions, and market influence.

One of the BFT, Behavioral life-cycle hypothesis, has been used to understand saving habits. The theory critiques the earlier conclusions in the life cycle hypothesis theory attributed to the classic economic studies of Modigliani (Ando \& Modigliani, 1963), who theorized that individuals plan their spending over their lifetimes, taking into account their future income. The arguments are that behavioral factors such as self-control affect savings through postponement of consumption, mental accounting leads to portioning of income between current and future use while framing tendencies are observed in wealth/income decision making whereby lump sum funds are treated separately from regular income. (Shefrin \& Thaler, 1988; Thaler \& Benartzi, 2004). Thus, BFT looks at decisions based on actual but not rational behavior. Several subsequent studies have associated the behavioral biases with sub-optimal financial decision-making; for example, studies suggest that consumers' preference for materialism leads to higher indebtedness as is the case with lack of self-control, which is an indicator of present biases affects long term planning and accumulation of wealth. (Ameriks, Caplin, Leahy, \& Tyler, 2007; Lown et al., 2015; Nye \& Hillyard, 2013). On the contrary, positive behavioral factors such as possession of self-control, confidence in use of financial information, deliberate thinking, optimism, willingness to take informed risks have been suggested to lead to optimal usage of financial services. (Benton et al., 2007; Gathergood, 2012; Strömbäck et al., 2017). Whereas most studies have adopted BFT to explain individuals' actual decisions regarding investments on assets traded in capital markets, a few such as (Waweru, Mwangi, \& Parkinson, 2014), have used the theory to explain decisions outside the financial markets. Following the line of thinking of (Binoy \& Subhahree, 2018; Strömbäck et al., 2017) among others, this study utilized BFT to identify an empirically test selected psychological and social factors that have been theorized to drive positive behaviors for optimal utilization of financial services by individuals outside the securities exchange markets; owners (or managers ) of micro-enterprises in Kenya.

The Financial Innovations (FINN) variable has been explained in prior studies using the Diffusion of Innovation (DOI) theory associated with French sociologist Gabriel Tarde, who plotted the original S-shaped diffusion curve, followed by Ryan and Gross (1943), who introduced the adopter categories that were later used in the current theory popularized by Everett Rogers. (Kaminski, 2011). Diffusion of innovation is the process that occurs as people adopt a new idea, product, practice, or philosophy, among others. Rogers (2004) reviewed the diffusion process and suggested the five categories of adopters of an innovation: innovators, early adopters, early majority, late majority, and laggards, however sometimes, a sixth group is added that is non-adopters. Beck (2016) suggested that FINN could be viewed from three dimensions. Firstly new delivery channels such as agency or correspondence banking and secondly new products such as those being provided by Insurance companies in liaison with other FFI.

Thirdly new types of financial intermediaries have emerged commonly telecommunication service providers who provide independent mobile-based financial services (Mpesa, Airtel Money, Telkom Kash, among many others) or in conjunction with banks (such as Mshwari, KCB Mpesa and many others in Kenya). Siddik, Sun, Yanjuan, and Kabiraj (2014) adopted DOI as well as the decomposed theory of planned behavior (modified by addition of a variable "perceived financial cost") to study factors influencing behavioral intention to adopt (or continue to use) mobile banking in Bangladesh. The findings of the study were that perceived financial cost, perceived risk, and subjective norm were the most influencing factors that affect people's behavioral intention to adopt (or continue to use) mobile banking, hence should be addressed for the country to realize universal FI. Al-Jabri and Sohail (2012) undertook a similar study using DOI as a baseline theory, whereas data was obtained from 330 actual mobile banking users. The findings of the study were that relative advantage, compatibility, and observability are responsible for adoption of the innovation. Trialability (innovation that 
allows experimentation on limited basis) and complexity had no significant effect on adoption whereas perceived risk causes negative impact on adoption of MFS. Similarly, Yeo and Fisher (2017) delved on the adoption and use of mobile financial services and their relationship with consumers' financial capability in the USA. The results of the study were that perceptions on usefulness, behavioral control, and subjective norms had significant effects on usage of the innovation and that financial capability was attributed to increased usage thereof. Jones et al. (2015) focused on the FINN in form of informational nudges on consumer credit card debt repayment behaviors in the USA. The findings suggest that disclosures required under the Credit Card Accountability Responsibility and Disclosure (CARD) Act introduced in 2009 were effective in inducing households to increase the amounts of credit card debt paid off each month, more so for those who pay off balances in full each month. Those who revolve credit from one month to another did not show significant change in behavior even with the introduction of the innovation. (Karlan et al., 2016) Had earlier undertaken a similar study focusing on effect of reminders on savings, data were collected from three settings (Philippines, Peru, and Bolivia). In the experiments clients were provided with monthly reminders to save towards a target, the findings were that on average the clients saved $6 \%$ more than individuals who did not, with a $\mathrm{p}$-value of 0.079 or 0.065 . The study did not find any significant difference between findings in each of the settings. The study theorized that reminders change intertemporal allocations, and improve consumer welfare, by providing associations between future expenditure opportunities and today's choices that mitigate the attentional failure. Hence, the predictions from their model were that reminders enhances saving more so when they focus on future goal or opportunity, thus validating the behavioral theories such as mental accounting. (Shefrin \& Thaler, 1988; Thaler \& Benartzi, 2004).

While considering factors that affect mobile banking (M-Banking) usage in Kenya (Lule, Omwansa, \& Waema, 2012) applied TAM to predict user's acceptance of information technology using two variables; perceived usefulness and perceived ease of use. Having surveyed four hundred and fifty (450) users of the innovation, the results suggest that the two variables had significant effects on customers' attitudes towards the financial product. FINN through prize-linked products have also been theorized to increase use of FS such as the study undertaken by Abraham et al. (2016) where they examined the effect of provision of lottery-linked deposit accounts (LLDAs), a savings scheme incorporating lottery-like payoffs to savings account holders, in Kenya. The study observed that there was an increase in account activity in form of additional deposits per day to enter into the lottery. The results suggest that LLDAs have the potential to enhance savings among the LIH and that product design has considerable implications on gambling behavior. Extensive empirical studies have also been undertaken effect of agency banking on usage of FS such as Mbugua (2015) among many others. Having reviewed the benefits and challenges associated with FINN, with a focus on digital finance/mobile financial services and its impact on FI and stability of financial system, Ozili (2018) felt short of subjecting the model to an empirical study. An attempt to test the model was undertaken through this study, excluding the effect on stability on FS which was modelled in the context of financial crisis to test contagion effects or otherwise. Having reviewed extant literature on FINN, FI and development, Kim, Zoo, Lee, and Kang (2018), observed that whereas there is growth, most of the studies are more aligned to delivery related issues (technology perspective) and less on impact on FI and socio-economic development, a course that was pursued in this research in a developing country setting. This study therefore considered the diffusion of innovation theory to be pertinent in explaining adoption of innovations in the financial sector in Kenya. Elements of the theory such as relative advantage, compatibility, complexity and observability were incorporated to the relevant section of the data collection tool. Therefore, premised on BFT and DOI theories and the literature review summarized above, the study hypothesized that:

$\mathrm{H}_{\mathrm{o}} 1$ : Financial Innovations does not have significant mediating effects on the relationship between Self-control and Financial Inclusion of Micro Enterprises in Kenya. 
$\mathrm{H}_{\mathrm{o}}$ 2: Financial Innovations does not have significant mediating effects on the relationship between Confidence and Financial Inclusion of Micro Enterprises in Kenya.

$\mathrm{H}_{\mathrm{o}} 3$ : Financial Innovations does not have significant mediating effects on the relationship between Social Proof and Financial Inclusion of Micro Enterprises in Kenya.

The conceptual framework this research is provided in Figure 1 below. The theoretical model shows the hypothesized relationship between the independent, mediating and dependent variables of the study. Usage of financial services (FI) was adopted as the dependent variable; the three behavioral factors, self-control, confidence and social proof were the independent variables whereas FINN formed the mediating variable. Factors that may affect the relationships among the variables under study (age, gender, and type of economic activity that a Micro Enterprise is mainly engaged in), all of which were derived from prior studies on the FI phenomenon, were included as control variables in the study model.

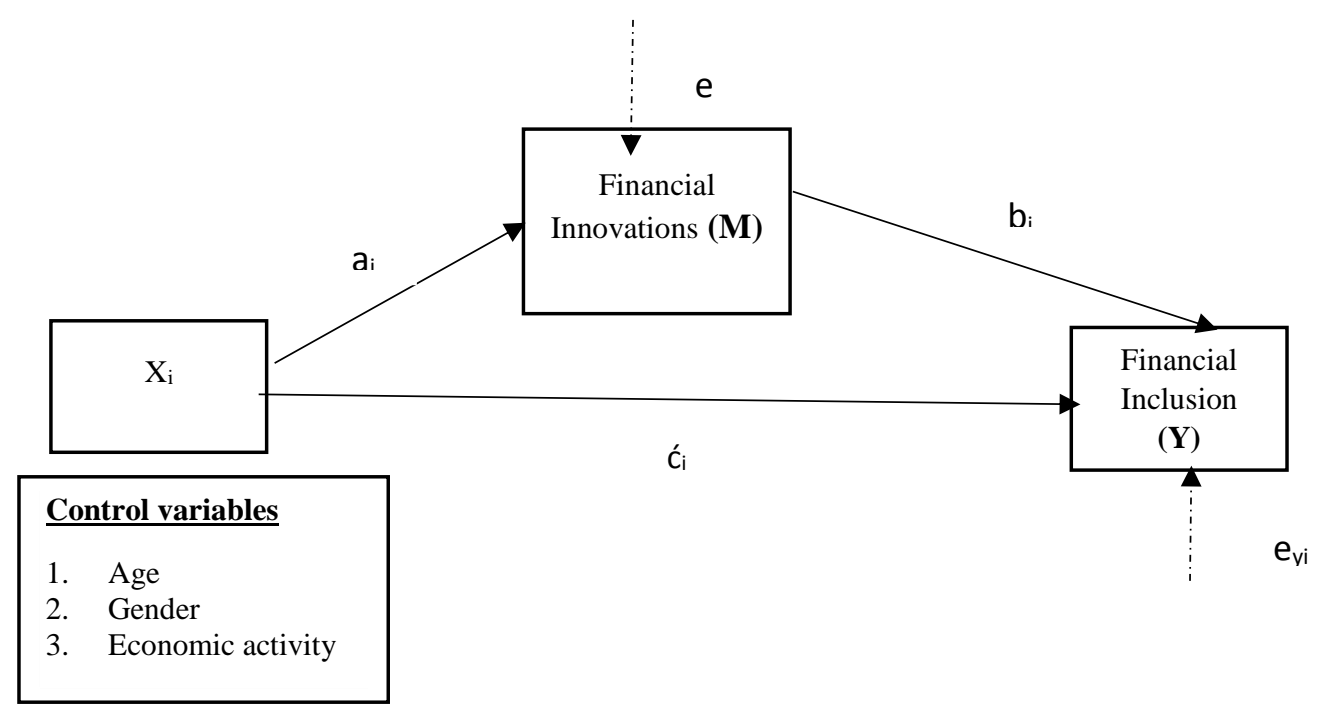

Figure 1 - Conceptual Framework

In Figure 1 above, $\mathrm{X}$ represents the three behavioral factors; $\mathrm{X}_{1}$ (self-control), $\mathrm{X}_{2}$ (Confidence), and $\mathrm{X}_{3}$ (Social proof), Financial innovations $(\mathrm{M})$ is the Mediator whereas Financial inclusion $(\mathrm{Y})$ is the independent variable. The direct effects of X on $\mathrm{Y}$ are represented by $c_{i}$ whereas the Indirect impact of $\mathrm{X}$ on $\mathrm{Y}$ through is $\mathrm{M}_{\mathrm{i}}$ is given by $a_{i}{ }^{*} b_{i}$. Tests were undertaken separately for each independent variable to test the three hypotheses developed for the study as outlined in the Introduction section above.

The two study models utilized by the study are outlined below. Equation 1 focuses on the mediating effects, whereas Equation 2 presents the complete model for predicting financial inclusion:

$\mathrm{M}=\mathrm{i}_{1}+\beta$ Gender $+\beta$ Age $+\beta$ Sector $+\mathrm{aX}+\mathrm{e}_{\mathrm{M}}$ Equation 1

Where; $\boldsymbol{M}=$ Mediator variable $(\mathrm{FINN}) ; \boldsymbol{i}_{1}=$ constant term or intercept; $\beta$ coefficients of Age, Gender, Economic activity, $\mathrm{a}=$ regression coefficients of $\mathrm{X}_{\mathrm{i}}$ ( Self-Control, Confidence or Social Proof) in the model ( effects of $\mathrm{X}_{\mathrm{i}}$ on $\mathrm{M}$ ); and $\boldsymbol{\varepsilon}_{M}=$ error term.

Besides, Equation 2 below was used to predict the values of the dependent variable (Financial Inclusion) while recognizing the mediating effects of FINN on the relationship between each of independent variables and Financial Inclusion, controlling for the effects of the covariates. The tests were undertaken separately for each of the independent variables (Self-control, Confidence and Social Proof). 
$\mathrm{Y}=\mathrm{i}_{2}+\beta$ Gender $+\beta$ Age $+\beta$ Sector $+c^{\prime} \mathrm{X} i+b$ FINN $+e_{Y}$ Equation 2

Where; $\boldsymbol{Y}=$ Financial Inclusion; $\boldsymbol{i}_{2}=$ constant term or intercept; $\beta$ coefficients of Age, Gender, Economic activity in the model; $\mathrm{c}^{\prime}=$ regression coefficients of $\mathrm{X}_{\mathrm{i}}$ (Self-Control, Confidence or Social Proof) in the model (direct effects of $\mathrm{X}_{\mathrm{i}}$ on $\left.\mathrm{Y}\right) ; \mathrm{b}=$ regression coefficients of FINN in the model; and $\varepsilon_{\mathrm{Y}}=$ error term.

\section{Methodology}

This study followed the positivist paradigm while employing explanatory research design given that quantitative data was collected to generate knowledge through testing the theories that grounded the study. (Creswell, 2014). Data from a sample of 486 out of 2,194 owners/representatives of licensed ME surveyed was used to draw inferences on opinions and trends on the indirect effects of behavioral factors on utilization of FFS by ME in Kenya, through adoption of financial innovations.For the selection of the sample, the study adopted stratified random sampling technique. The sample size for each type of economic activity was determined by using the ratio of the micro-enterprises in each stratum versus the entire population multiplied by the sample size of 486 . Therefore, primary data was collected using a structured questionnaire administered by the researcher and her assistants. The survey encompassed both positive and negatively worded items for the Likert type questions, the latter of which was included to minimize response bias given that they enable respondents to be more engaged in the items instead of automatic response. Data was successfully collected from 413 respondents, thus a response rate of 84.9 percent of the target sample. A detailed review of the data captured in the study database was undertaken to assess whether there were missing and out of range data. The results of descriptive statistics tests conducted within SPSS indicated that there were no missing data to call for correction mechanisms. To determine cases with extreme values concerning multiple variables, Cook's and Mahalanobis distance tests within SPSS were utilized. Cases with the highest Mahalanobis distances values (probability less than 1 percent) and those whose Cook's distance values were greater than one were further examined and winsorized to avoid impact on the models. (Garson, 2012).

\section{Data Measurement}

Financial inclusion was measured through perceptions on the usage of payment services, money transfer services, savings, credit and investments made through formal financial institutions. Usage of these services was expected to be outcomes of optimal decision making arising from positive behavioral factors, mediated by adoption of financial innovations and moderated by possession of requisite financial knowledge and skills. This study measured BF using three variables: self-control, confidence, social proof based on items in the data collection tool all of which have been tested and considered reliable by other studies. (Fernandes, Lynch Jr, \& Netemeyer, 2014; Nye \& Hillyard, 2013; Strömbäck et al., 2017). Arising from the emerging research on FINN, the phenomenon was measured using perceptions on effects of emerging products, new channels, and intermediaries as well as information on usage of FS. The items that form the measure of the effect of FINN on usage of FS were documented in the questionnaire, all of which were derived from prior studies such as (Mbugua, 2015; Siddik et al., 2014) as modified to suit the present study. FINN was modelled to mediate the relationship between $\mathrm{BF}$ and usage of financial services (FI). The control variables for the study were the age and gender of the ME owner/managers as well as the main economic activity being undertaken by the business. Age was measured in terms of years whereas gender was measured as either male or female as was used in FSD (2016);KNBS (2016). Economic activities were categorized as manufacturing, commercial/trade, as well as service and other sectors. To inform the identification of the relevant economic activity category, sampled ME were requested to select one industry based on their highest source of income in the previous year, as was adopted by KNBS (2016).

The above measures were validated, and their reliability tested using factor analyzing and Cronbach alpha and presented in Table 1. The principal component analysis with varimax rotation was performed to identify the 
underlying factors for variables. The results depicted high factor loading scores by all items that were all above the minimum recommended value of .50. (Hair, Black, Babin, \& Anderson, 2014). As outlined in Table 1, the loadings of the items were above .5 hence all the items were considered essential in explaining the financial inclusion, social proof, confidence and self-control constructs. The Exploratory Factor Analysis cumulative extracted variance was above 50\% (Hair et al., 2014; Yong \& Pearce, 2013). Thus, all the items were considered appropriate to explain the variable.

Table 1 - Reliability and Validity of Data Measurements

\begin{tabular}{|c|c|c|c|c|c|c|c|}
\hline$n=413$ & $\begin{array}{l}\text { Cronbach's } \\
\text { Alpha }\end{array}$ & KMO & $\begin{array}{l}\text { Bartlett's Test of } \\
\text { Sphericity }\end{array}$ & Mean & loadings & AVE & CV\% \\
\hline Financial Inclusion & .731 & .694 & $2063.81 *$ & 3 & & 0.83 & 84.84 \\
\hline FI1 & & & & 2.55 & 0.98 & & \\
\hline FI2 & & & & 2.66 & 0.96 & & \\
\hline FI3 & & & & 2.67 & 0.96 & & \\
\hline FI4 & & & & 2.67 & 0.90 & & \\
\hline FI5 & & & & 3.04 & 0.91 & & \\
\hline FI6 & & & & 3.23 & 0.85 & & \\
\hline FI7 & & & & 3.62 & 0.83 & & \\
\hline Self-Control & .887 & .783 & $1662.839 *$ & 3.00 & & 0.69 & 69.40 \\
\hline SC1 & & & & 3.45 & 0.93 & & \\
\hline SC2 & & & & 3.44 & 0.91 & & \\
\hline $\mathrm{SC3}$ & & & & 3.38 & 0.79 & & \\
\hline SC4 & & & & 3.28 & 0.79 & & \\
\hline SC5 & & & & 3.25 & 0.73 & & \\
\hline Confidence & .929 & .78 & $2316.59 *$ & 3.09 & & 0.64 & 78.02 \\
\hline $\mathrm{C1}$ & & & & 3.63 & 0.91 & & \\
\hline $\mathrm{C} 2$ & & & & 3.62 & 0.90 & & \\
\hline $\mathrm{C3}$ & & & & 3.61 & 0.88 & & \\
\hline C4 & & & & 3.56 & 0.87 & & \\
\hline C5 & & & & 3.55 & 0.86 & & \\
\hline Social proof & .915 & .732 & $2043.80 *$ & 3.13 & & 0.75 & 74.70 \\
\hline SP1 & & & & 3.68 & 0.87 & & \\
\hline SP2 & & & & 3.66 & 0.86 & & \\
\hline SP3 & & & & 3.57 & 0.88 & & \\
\hline SP4 & & & & 3.55 & 0.86 & & \\
\hline SP5 & & & & 3.53 & 0.84 & & \\
\hline Financial Innovations & .920 & .729 & $7178.931 *$ & 3.17 & & 0.40 & 87.06 \\
\hline FINN1 & & & & 3.27 & 0.82 & & \\
\hline FINN2 & & & & 3.25 & 0.91 & & \\
\hline FINN3 & & & & 3.22 & 0.94 & & \\
\hline FINN4 & & & & 3.21 & 0.88 & & \\
\hline FINN5 & & & & 3.21 & 0.93 & & \\
\hline FINN6 & & & & 3.20 & 0.96 & & \\
\hline FINN7 & & & & 3.20 & 0.93 & & \\
\hline FINN8 & & & & 3.20 & 0.89 & & \\
\hline FINN9 & & & & 3.20 & 0.93 & & \\
\hline FINN10 & & & & 3.19 & 0.93 & & \\
\hline
\end{tabular}

$*_{p}<0.05$ 
Moreover, Bartlett's Test of Sphericity produced a significant Chi-Square $\left(\chi^{2}\right)(\varrho<.05)$ and Kaiser - Meyer Olkin measure of sampling adequacy above the acceptable value of .5, (Field, 2005), showing that it was appropriate to subject data for factor analysis on this variable of social proof, confidence and self-control construct. Having observed that all items met the criteria are supported by finance theory and statistical analysis in terms of loading, Eigen values and significant contribution to the explained total variance they were all retained for further analysis. Cronbach alpha for each variable based on the average of inter-item correlation was above .70 .

\section{Results}

\section{Bivariate Analysis}

Table 2 shows the results of data transformation undertaken on the study variables. From the findings, Social proof had the highest mean (3.129) followed by Confidence (3.092). Financial inclusion and Self-control both had a way of (3.001), while Financial Innovation had the lowest mean of (2.998). The implication is that the social proof exhibited itself as a superior behavioral factor in enhancing usage of financial services thus enhancing financial inclusion of micro-enterprises in Kenya. The standard deviations for all the variables were less than 1 indicating fewer variations in the responses. Finally, all the independent variables, mediator and dependent variables were normally distributed as demonstrated in Table 2 below.

Furthermore, the results, as outlined in Table 2 below indicates that there is a positive and significant correlation between the independent variables and financial inclusion. Notably, the correlation results showed that Selfcontrol had a positive and significant moderate relationship with financial inclusion $(r=.592, \varrho<.01)$. Confidence positively correlated with financial inclusion $(r=.561, \varrho<.01)$. Moreover, results indicate that Social proof undoubtedly and significantly relates to financial inclusion $(r=.545, \varrho<.01)$. Also financial innovation is positively and significantly correlated with financial inclusion $(r=.388, \varrho<.01)$. Gender $(r=.0 .021, \varrho>.01)$ and age $(r=.007, \varrho>.01)$ respectively showed a positive but insignificant correlation with financial inclusion, whereas sector had a negative but insignificant relationship with the dependent variable $(r=-.001 ; \varrho>.05)$. Based on the above results there is an indication of linear relationship between all predictor variables on the predicted variable (financial inclusion) of micro-enterprises in Kenya. Hence there needs to perform advanced analysis through multiple regression models to show the cause-effect relationships.

Table 2 - Correlation Analysis

\begin{tabular}{|c|c|c|c|c|c|c|c|c|c|c|c|}
\hline$n=413$ & Mean & Std & Skew & FI & SC & C & SP & FINN & gender & age & sector \\
\hline FI & 3.001 & 0.623 & 0.232 & 1 & & & & & & & \\
\hline SC & 3.001 & 0.752 & -0.116 & $.592 * *$ & 1 & & & & & & \\
\hline C & 3.092 & 0.776 & -0.183 & $.561 * *$ & $.450 * *$ & 1 & & & & & \\
\hline SP & 3.129 & 0.772 & -0.274 & $.545^{* *}$ & $.471 * *$ & $.404 * *$ & 1 & & & & \\
\hline FINN & 2.998 & 0.695 & -0.149 & $.385^{* *}$ & $.388^{* *}$ & $.372 * *$ & $.389 * *$ & 1 & & & \\
\hline Gender & 1.43 & 0.496 & 0.27 & 0.021 & 0.007 & 0.054 & 0.038 & 0.043 & 1 & & \\
\hline Age & 1.68 & 0.745 & 0.924 & 0.007 & 0.029 & 0.03 & 0.036 & -0.033 & $.441 * *$ & 1 & \\
\hline Sector & 2.28 & 0.524 & 0.199 & -0.001 & -0.002 & -0.045 & -0.057 & -0.029 & $.226 * *$ & $.245^{* *}$ & 1 \\
\hline
\end{tabular}

The labels of the variables used in Table 2 above and following tables were; FI= Financial inclusion, SC $=$ Selfcontrol, $\mathrm{C}=$ Confidence, $\mathrm{SP}=$ Social proof, and FINN= Financial Innovations. 


\section{Hypotheses Testing}

The main objective of the study was to establish the mediating effects of Financial Innovations on the relationship between behavioral factors (self-control, confidence, and social proof) and financial inclusion. The results of the tests conducted on the three hypotheses and interpretations are provided in the sections below. The mediation analysis was performed using Model 4 of Hayes (2013) and descriptions made using the arguments of Zhao, Lynch Jr, and Chen (2010); Hayes (2013) that presence of mediation effects is determined by focusing on the significance of the indirect impact arising from bootstrap test which is considered more superior to earlier ones such as Sobel Test. The results for each of the independent variables are discussed below:

\section{Financial Innovations on the Self-Control and Financial Inclusion Relationship}

The results of the hypothesis testing using Model 4 of Process Macro are summarized in Table 3 below. The results demonstrate that the indirect effect of self-control on financial inclusion, through financial innovations was significant $(\beta=.0941, \varrho=0.00)$. Therefore, based on the study results, hypothesis $\mathrm{H}_{0} 1$ was rejected. The study concluded that adoption of financial innovations has significant mediating effects on the relationship between self-control tendencies and financial inclusion of micro-enterprises in Kenya.

Table 3 - Self-control, Financial Innovations and Financial Inclusion

\begin{tabular}{|c|c|c|c|}
\hline \multicolumn{4}{|c|}{ Standardized Coefficients } \\
\hline & Outcome variable : FINN & Outcome variable: FI & Indirect effect: \\
\hline & Coeff & Coeff & Coeff $\left(a^{*} \mathrm{~b}\right)$ \\
\hline (Constant) & -.0583 & -.0208 & \\
\hline Gender & .0474 & -.0036 & \\
\hline Age & -.0531 & .0089 & \\
\hline Sector & -.0499 & .0038 & \\
\hline Self-control & $.3188^{* *}$ & $.4461^{* *}$ & \\
\hline Financial Innovation & & $.2953^{* *}$ & \\
\hline Indirect effect: & & & $0.0941^{* *}$ \\
\hline \multicolumn{4}{|l|}{ Coeff $(a * b)$} \\
\hline \multicolumn{4}{|c|}{ Model Summary: Outcome Variable FI } \\
\hline $\mathbf{R}$ & .6040 & & \\
\hline R Square & .3648 & & \\
\hline MSE & .6482 & & \\
\hline \multicolumn{4}{|l|}{ ANOVA; model fitness } \\
\hline $\mathbf{F}$ & 46.7443 & & \\
\hline Sig. & .0000 & & \\
\hline \multicolumn{4}{|c|}{ Direct effect of self-control on Financial Inclusion $(\mathrm{FI})=.4461^{* *}$} \\
\hline \multicolumn{4}{|c|}{ Indirect effect of self-control on FI $\left(a^{*} \mathrm{~b}\right)=0.0941^{* *}$} \\
\hline \multicolumn{4}{|c|}{ ** Coeff significant at the 0.05 level (2-tailed). } \\
\hline \multicolumn{4}{|c|}{ Number of bootstrap samples for percentile bootstrap confidence intervals:5000 } \\
\hline
\end{tabular}

\section{Financial Innovations on Confidence and Financial Inclusion relationship}

The results outlined in Table 4 below indicates that Confidence has a significant indirect effect on financial inclusion through financial innovations $(\beta=.1019, \varrho=0.00)$. Therefore, hypothesis $\mathrm{H}_{0} 2$ was rejected, and the study concluded that adoption of financial innovations has significant mediating effects on the relationship between Confidence behaviors and financial inclusion of micro-enterprises in Kenya. 
Table 4 - Confidence, Financial Innovations and Financial Inclusion

\begin{tabular}{|c|c|c|c|}
\hline & \multicolumn{3}{|l|}{ Standardized Coefficients } \\
\hline & Outcome variable : FINN & Outcome variable: FI & Indirect effect: \\
\hline & Coeff & Coeff & Coeff $\left(a^{*} b\right)$ \\
\hline (Constant) & -.0372 & .0073 & \\
\hline Gender & .0160 & -.0393 & \\
\hline Age & -.0542 & .0080 & \\
\hline Sector & -.0301 & .0229 & \\
\hline Confidence & $.3894^{* *}$ & $.4471^{* *}$ & \\
\hline Financial Innovation & & $.2617^{* *}$ & \\
\hline \multicolumn{4}{|l|}{ Indirect effect: } \\
\hline Coeff $(a * b)$ & & & $0.1019^{* *}$ \\
\hline \multicolumn{4}{|c|}{ Model Summary: Outcome Variable FI } \\
\hline $\mathbf{R}$ & .5959 & & \\
\hline R Square & .3551 & & \\
\hline MSE & 6581 & & \\
\hline \multicolumn{4}{|l|}{ ANOVA; model fitness } \\
\hline F & 44.8245 & & \\
\hline Sig. & .0000 & & \\
\hline \multicolumn{4}{|c|}{$\begin{array}{l}\text { Direct effect of Confidence on FI }=0.4471^{* *} \text {, Indirect effect of Confidence on FI }\left(a^{*} \mathrm{~b}\right)=0.1019^{* *} \\
* * \text { Coeff significant at the } 0.05 \text { level (2-tailed). }\end{array}$} \\
\hline
\end{tabular}

\section{Financial Innovations on Social proof and Financial Inclusion relationship}

The final tests of mediating effects were undertaken to test hypothesis $\mathrm{H}_{0} 3$ that Financial Innovations does not have significant mediating effects on the relationship between social proof and Financial Inclusion of Micro Enterprises in Kenya. The results outlined in Table 5 below indicates that Social proof has a significant indirect effect on financial inclusion through financial innovations $(\beta=.1036, \varrho=0.00)$. Therefore, hypothesis $\mathrm{H}_{0} 3$ was rejected, and the study concluded that adoption of financial innovations has significant mediating effects on the relationship between Social proof behaviors and financial inclusion of micro-enterprises in Kenya.

Table 5 - Social proof, Financial Innovations, and Financial Inclusion

\begin{tabular}{|c|c|c|c|}
\hline \multicolumn{4}{|c|}{ Standardized Coefficients } \\
\hline & Outcome variable : FINN & Outcome variable: FI & Indirect effect: \\
\hline & Coeff & Coeff & Coeff $\left(a^{*} b\right)$ \\
\hline (Constant) & -.0340 & .0120 & \\
\hline Gender & .0393 & -.0139 & \\
\hline age & -.0633 & .0000 & \\
\hline sector & -.0344 & .0188 & \\
\hline Social proof & $.3511^{* *}$ & $.3868^{* *}$ & \\
\hline Financial Innovation & & $.2952^{* *}$ & \\
\hline \multicolumn{4}{|l|}{ Indirect effect: } \\
\hline Coeff $(a * b)$ & & & $0.1036^{* *}$ \\
\hline \multicolumn{4}{|c|}{ Model Summary: Outcome Variable FI } \\
\hline $\mathbf{R}$ & .5681 & & \\
\hline R Square & .3227 & & \\
\hline MSE & 6911 & & \\
\hline \multicolumn{4}{|l|}{ ANOVA; model fitness } \\
\hline $\mathbf{F}$ & 38.7895 & & \\
\hline Sig. & .0000 & & \\
\hline \multicolumn{4}{|c|}{$\begin{array}{l}\text { Direct effect of Social proof on FI }=.3868^{* *} \text {, Indirect effect of Social proof on FI }\left(\mathrm{a}^{*} \mathrm{~b}\right)=.1036^{* *} \\
* * \text { Coeff significant at the } 0.05 \text { level }(2 \text {-tailed). }\end{array}$} \\
\hline
\end{tabular}




\section{Discussion}

Tests on the three hypotheses demonstrated positive and significant mediating effects of financial innovations on the relationships between the independent variables and financial inclusion (DV). The results showed that financial innovations mediate the relationship between Self-control and Financial Inclusion $(\beta=.0941, \varrho=0.00)$, Confidence and FI $(\beta=1019, \varrho=0.00)$ as well as Social proof and FI $(\beta=.1036, \varrho=0.00)$. The findings are supported by those of earlier studies such as Siddik et al. (2014), who argued that adoption of emerging financial innovation increases the efficiency of the individual account holder by saving time as well as eliminating space shortcomings to access bank services. The results are also in line with those of Wentzel, Diatha, and Yadavalli (2013), who suggested that behavioral factors significantly affect adoption of technology-enabled financial services (mobile banking), which have the potential to expand financial inclusion, especially for low-income households. Similarly, Yeo and Fisher (2017) delved on the adoption of innovation and their relationship with consumers' financial capability and observed significant effects of perceived behavioral control, subjective norms, and perceived usefulness on adoption of mobile financial services, with increased usage being attributed to higher level of financial capability. Also, Yang, Lu, Gupta, Cao, and Zhang (2012), had similar findings and suggested that behavioral beliefs in combination with social influences and personal traits are all important determinants for mobile payment services adoption and usage.

\section{Conclusion}

The results showed that financial innovations mediate the relationship between each of the behavioral factors and financial inclusion. Thus, the study concluded that financial innovations such a mobile money, agency banking, emerging financial products among others has not only opened up new opportunities for the MEs but also increased new market and availability of innovative financial services products all of which contribute to optimal financial decision, opportunities for growth as well as economic development. The study established that enhanced FI could be realized if users of FS have positive behavioral factors in addition to adoption of appropriate emerging financial products and intermediary channels.

\section{Managerial and Policy Implication}

Based on the findings the following are recommended;

- Formal Financial Services institutions and business associations such as Kenya bankers association, association of Kenya insurers, Kenya Union of Savings and Credit Cooperatives Society (KUSCCO) among others, should make use of the findings of this study to appreciate the critical role of financial innovations in carrying the effects of positive behavioral factors to higher levels of financial inclusion. Whereas these institutions have been cooperating with other service providers such as mobile finance providers (Safaricom, Airtel, Telkom Kenya, among others), it is recommended that these new products and dissemination of information thereof be aligned in a manner that builds on MEs behavioral traits to create more value. BFT attest that human being is influenced by psychological and social factors.

- Furthermore, innovative products that spur confidence, appeals to owners of MEs and their circle of friends/family, encourage planning and responsible credit use, among others, should continually the developed in order to create sustainable benefits to FFS institutions in the long run, instead of championing emerging financial innovations for the sake of making quick wins.

\section{Theoretical implication}

The research findings of this study have several effects for academicians and others involved in theory building on factors that matter for enhanced FI, given that the mediating role of financial innovation on the relationship 
between behavioral factors and usage of financial services, was empirically tested hence basis for further research by finance scholars. Furthermore, the study attempted to contribute to growth in financial theory by formulating and testing of a more comprehensive framework that incorporated seldom-studied drivers of financial inclusion from an emerging economy.

\section{Future Research}

The study offers a significant contribution to academic research and practices. However, it had some limitations that open up opportunities for further future research. Firstly, the hypotheses were tested after controlling for variables derived from previous studies (ME owners' gender and age as well as the economic sector that the firms were mostly engaged in for internal validity of results. However, there is need to consider other factors that have been suggested to have effects on financial inclusion to confirm the generalizability of the model. Secondly, the data provided by Nairobi County Government excluded micro-enterprises that have not been licensed. These unlicensed firms could be many hence need to consider undertaking a study that collects data from both licensed and unlicensed Microenterprises to compare the findings with those of this study.

Thirdly, further studies should be undertaken on other behavioral factors to develop a more comprehensive framework for understanding the role of behavioral factors in enhancing financial inclusion. Finally, finance theory has different dimensions of financial inclusion, which were not incorporated in this study such as quality of services offered by financial institutions. Therefore, future studies should move beyond access and usage of financial services and focus on the quality dimension of financial inclusion to enhance the growth of finance theory on the concept.

Funding: This research received no external funding.

Acknowledgments: In this section, you can acknowledge any support given which is not covered by the author's contribution or funding sections. This may include administrative and technical support, or donations in kind (e.g., materials used for experiments).

Conflicts of Interest: The authors declare no conflict of interest

\section{References}

Abraham, J., Akbas, M., Ariely, D., \& Jang, C. (2016). Using Lotteries to Encourage Saving: Experimental Evidence from Kenya.

Al-Jabri, I. M., \& Sohail, M. S. (2012). Mobile banking adoption: Application of diffusion of innovation theory. Journal of Electronic Commerce Research, 13(4), 379-391.

Allen, F., Demirguc-Kunt, A., Klapper, L., \& Peria, M. S. M. (2016). The foundations of financial inclusion: Understanding ownership and use of formal accounts. Journal of Financial Intermediation, 27(C), 1-30.

Ameriks, J., Caplin, A., Leahy, J., \& Tyler, T. (2007). Measuring self-control problems. American Economic Review, 97(3), 966-972.

Ando, A., \& Modigliani, F. (1963). The" life cycle" hypothesis of saving: Aggregate implications and tests. The American economic review, 53(1), 55-84.

Atalay, K., Bakhtiar, F., Cheung, S., \& Slonim, R. (2014). Savings and prize-linked savings accounts. Journal of Economic Behavior \& Organization, 107, 86-106.

Barber, B. M., \& Odean, T. (2007). All that glitters: The effect of attention and news on the buying behavior of individual and institutional investors. The review of financial studies, 21(2), 785-818.

Beck, T. (2016). Financial Inclusion-Measuring progress and progress in measuring. Paper presented at the This paper was written for the Fourth IMF Statistical Forum "Lifting the Small Boats: Statistics for Inclusive Growth. Cass Business School, City, University of London, CEPR, and CESifo. 
Benton, J. E., Byers, J., Cigler, B. A., Klase, K. A., Menzel, D. C., Salant, T. J., . . Waugh Jr, W. L. (2007). Conducting research on counties in the 21st century: A new agenda and database considerations. Public administration review, 67(6), 968-983.

Binoy, T., \& Subhahree, N. (2018). Behavioural Factors that Influence the Continued Usage of Formal Financial Services Among The Low Income Households. International Journal of Mechanical Engineering and Technology, 9(7), 22-36.

Cadena, X., \& Schoar, A. (2011). Remembering to pay? Reminders vs. financial incentives for loan payments: National Bureau of Economic Research.

Chambers, C. (2010). Financial Exclusion and Banking Regulation in the UK: Template Analysis: Lambert Academic Pub.

Creswell, J. W. (2014). A concise introduction to mixed methods research: SAGE publications.

Demirguc-Kunt, A., \& Klapper, L. (2012). Measuring financial inclusion: The global findex database: The World Bank.

Demirguc-Kunt, A., Klapper, L., Singer, D., Ansar, S., \& Hess, J. (2018). The Global Findex Database 2017: Measuring financial inclusion and the fintech revolution: The World Bank.

Faye, I., \& Triki, T. (2013). Financial Inclusion in Africa: The transformative role of technology. Ghana. African Development Bank (AfDB).

Fernandes, D., Lynch Jr, J. G., \& Netemeyer, R. G. (2014). Financial literacy, financial education, and downstream financial behaviors. Management Science, 60(8), 1861-1883.

Francis, E., Blumenstock, J., \& Robinson, J. (2017). Digital credit: A snapshot of the current landscape and open research questions. CEGA White Paper.

FSD. (2016). Central Bank of Kenya, Kenya National Bureau of Statistics, FinAccess Household Survey 2015. Harvard Dataverse, 4.

Garson, G. D. (2012). Testing statistical assumptions. Asheboro, NC: Statistical Associates Publishing.

Gathergood, J. (2012). Debt and depression: causal links and social norm effects. The Economic Journal, 122(563), 1094-1114.

Grohmann, A. (2018). Financial literacy and financial behavior: Evidence from the emerging Asian middle class. Pacific-Basin Finance Journal, 48, 129-143.

Hair, J. F., Black, W. C., Babin, B. J., \& Anderson, R. E. (2014). Multivariate data analysis: Harlow. UK: Pearson Education Limited.

Hayes, A. F. (2013). Introduction to mediation, moderation, and conditional process analysis: Methodology in the Social Sciences. Kindle Edition, 193.

Jones, L. E., Loibl, C., \& Tennyson, S. (2015). Effects of informational nudges on consumer debt repayment behaviors. Journal of Economic Psychology, 51, 16-33.

Jukan, M. K., \& Softic, A. (2016). Comparative analysis of financial inclusion in developing regions around the world. Economic Review: Journal of Economics and Business, 14(2), 56-65.

Jurevičienè, D., \& Ivanova, O. (2013). Behavioural finance: theory and survey/Finansine elgsena: teorija ir tyrimas. Mokslas-Lietuvos ateitis/Science-Future of Lithuania, 5(1), 53-58.

Kaminski, J. (2011). Diffusion of innovation theory. Canadian Journal of Nursing Informatics, 6(2), 1-6.

Karlan, D., McConnell, M., Mullainathan, S., \& Zinman, J. (2016). Getting to the top of mind: How reminders increase saving. Management Science, 62(12), 3393-3411.

Karlan, D., Morten, M., \& Zinman, J. (2012). A personal touch: Text messaging for loan repayment: National Bureau of Economic Research.

Karp, N., \& Nash-Stacey, B. (2015). Technology, Opportunity \& Access: Understanding Financial Inclusion in the US. BBVA Research paper(15/25).

Kast, F., Meier, S., \& Pomeranz, D. (2018). Saving more in groups: Field experimental evidence from Chile. Journal of Development Economics, 133, 275-294. 
Kim, M., Zoo, H., Lee, H., \& Kang, J. (2018). Mobile financial services, financial inclusion, and development: A systematic review of academic literature. The Electronic Journal of Information Systems in Developing Countries, 84(5), e12044.

KNBS. (2016). Micro, Small and Medium Establishment (MSME) Survey Basic Report.

Lanie, T. (2017). Demand-driven determinants and self-reported barriers to financial inclusion in the West African Economic and Monetary Union (WAEMU). Journal of Economics and International Finance, 9(11), 120-130.

Lown, J. M., Kim, J., Gutter, M. S., \& Hunt, A.-T. (2015). Self-efficacy and savings among middle and low income households. Journal of Family and Economic Issues, 36(4), 491-502.

Lule, I., Omwansa, T. K., \& Waema, T. M. (2012). Application of technology acceptance model (TAM) in mbanking adoption in Kenya. International Journal of Computing \& ICT Research, 6(1).

Mbugua, S. (2015). Role of Agent Banking Services in Promotion of Financial Inclusion in Nyeri Town Kenya. Research Journal of Finance and Accounting, 6(3), 2222-2847.

Meier, S., \& Sprenger, C. (2010). Present-biased preferences and credit card borrowing. American Economic Journal: Applied Economics, 2(1), 193-210.

Neaime, S., \& Gaysset, I. (2018). Financial inclusion and stability in MENA: Evidence from poverty and inequality. Finance Research Letters, 24, 230-237.

Nye, P., \& Hillyard, C. (2013). Personal financial behavior: The influence of quantitative literacy and material values. Numeracy, 6(1), 3.

Olaniyi, E., \& Babatunde, A. (2016). Determinants of Financial Inclusion in Africa: A Dynamic Panel Data Approach. University of Mauritius Research Journal, 22, 310-336.

Ozili, P. K. (2018). Impact of digital finance on financial inclusion and stability. Borsa Istanbul Review, 18(4), $329-340$.

Park, C.-Y., \& Mercado, R. (2015). Financial inclusion, poverty, and income inequality in developing Asia. Asian Development Bank Economics Working Paper Series(426).

Rogers, E. M. (2004). A prospective and retrospective look at the diffusion model. Journal of health communication, 9(S1), 13-19.

Ryan, B., \& Gross, N. C. (1943). The diffusion of hybrid seed corn in two Iowa communities. Rural sociology, $8(1), 15$.

Sarma, M. (2008). Index of financial inclusion: Working paper.

Sethi, D., \& Acharya, D. (2018). Financial inclusion and economic growth linkage: Some cross country evidence. Journal of Financial Economic Policy, 10(3), 369-385.

Shefrin, H. M., \& Thaler, R. H. (1988). The behavioral life-cycle hypothesis. Economic inquiry, 26(4), 609-643.

Siddik, M. N. A., Sun, G., Yanjuan, C., \& Kabiraj, S. (2014). Financial inclusion through mobile banking: a case of Bangladesh. Journal of Applied finance and Banking, 4(6), 109.

Strömbäck, C., Lind, T., Skagerlund, K., Västfjäll, D., \& Tinghög, G. (2017). Does self-control predict financial behavior and financial well-being? Journal of Behavioral and Experimental Finance, 14, 30-38.

Thaler, R. H., \& Benartzi, S. (2004). Save more tomorrow ${ }^{\text {TM}}$ : Using behavioral economics to increase employee saving. Journal of political Economy, 112(S1), S164-S187.

Thrift, N., \& Leyshon, A. (1999). Moral geographies of money. Nation-States and Money: The Past, Present and Future of National Currencies. London, Routledge, 159-181.

Waweru, N. M., Mwangi, G. G., \& Parkinson, J. M. (2014). Behavioural factors influencing investment decisions in the Kenyan property market. Afro-Asian Journal of Finance and Accounting, 4(1), 26-49.

Wentzel, J. P., Diatha, K. S., \& Yadavalli, V. S. S. (2013). An application of the extended Technology Acceptance Model in understanding technology-enabled financial service adoption in South Africa. Development Southern Africa, 30(4-5), 659-673. 
Yang, S., Lu, Y., Gupta, S., Cao, Y., \& Zhang, R. (2012). Mobile payment services adoption across time: An empirical study of the effects of behavioral beliefs, social influences, and personal traits. Computers in Human Behavior, 28(1), 129-142.

Yeo, J. H., \& Fisher, P. J. (2017). Mobile financial technology and consumers' financial capability in the United States. Journal of Education \& Social Policy, 7(1), 80-93.

Yong, A. G., \& Pearce, S. (2013). A beginner's guide to factor analysis: Focusing on exploratory factor analysis. Tutorials in quantitative methods for psychology, 9(2), 79-94.

Zaleskiewicz, T. (2006). Behavioral finance. Handbook of Contemporary Behavioral Economics, New York: Sharpe, $706,728$.

Zhao, X., Lynch Jr, J. G., \& Chen, Q. (2010). Reconsidering Baron and Kenny: Myths and truths about mediation analysis. Journal of consumer research, 37(2), 197-206.

Zins, A., \& Weill, L. (2016). The determinants of financial inclusion in Africa. Review of Development Finance, 6(1), 46-57. 